\title{
AS INCUBADORAS UNIVERSITÁRIAS DE ECONOMIA SOLIDÁRIA DURANTE A PANDEMIA: RELATO DE AÇÕES DA INCUBES/UFPB E DA INCUBACOOP/UFRPE ${ }^{1}$
}

Júlia Figueredo Benzaquen² Vanderson Carneiro 3 Maurício Sardá 4

\section{INTRODUÇÃO}

Este texto apresenta algumas açôes realizadas por duas universidades da região Nordeste no enfrentamento à atual pandemia da Covid-19. Essas atividades são frutos de relaçôes que as universidades possuíam antes da pandemia e que, por conta do contexto adverso provocado pelo novo coronavírus, se adaptaram e se reestruturaram para o melhor enfrentamento das novas adversidades. Mantendo os princípios de fortalecimento do tripé universitário entre ensino-pesquisa-extensão, entendendo extensão como comunicação e não invasão (Freire, 2006) e apostando em processos de ecologia dos saberes (Santos, 2006), as açôes são desenvolvidas em diálogo com os parceiros e a partir de suas próprias demandas.

Destacamos primeiramente as açôes da Incubadora de Empreendimentos Solidários (Incubes), do Núcleo Interdisciplinar de Pesquisa e Extensão em Economia Solidária e Educação Popular (Nuplar), da Universidade Federal da Paraíba (UFPB), que apresenta quatro grandes blocos de atividades em desenvolvimento neste período, desde o apoio aos empreendimentos coletivos de economia solidária, formação de redes e espaços virtuais de comercialização, e açôes no campo da segurança e soberania alimentar e nutricional, com destaque para o levantamento de informaçóes sobre a situação de segurança alimentar de uma comunidade tradicional (Povos de Terreiro) e a continuidade de curso de extensão à distância sobre o tema.

Em Pernambuco, destacam-se as açóes da Incubadora Tecnológica de Cooperativas Populares (Incubacoop) da Universidade Federal Rural de Pernambuco (UFRPE), no território de Bonito, com o apoio e a assessoria técnica a agricultores(as) familiares em processo de transição agroecológica, e a participação na implementação e no funcionamento do projeto Mercado da Vida, em parceria com a prefeitura municipal e as associaçóes locais. Além dessa ação de incubação territorial, professores que integram a incubadora participam de uma iniciativa estruturante que vem se materializando na constituição da Universidade Popular dos Movimentos Sociais (UPMS), por meio de uma parceria de setores da universidade com movimentos sociais e organizaçôes não governamentais (ONGs). O último eixo compreende

1. DOI: http://dx.doi.org/10.38116/bmt69/economiasolidaria2

2. Professora do Departamento de Ciências Sociais e membro da Incubacoop/UFRPE. E-mail: <juliabenzaquen@gmail.com>.

3. Professor do Departamento de Gestão Pública e membro da Incubes/Nuplar/UFPB. E-mail: <vandersonces@gmail.com>.

4. Professor do Departamento de Ciências Sociais e membro da Incubacoop/UFRPE.E-mail: <mausarda@gmail.com>. 
as açôes no campo da segurança alimentar realizadas no âmbito do Projeto Fortalecimento do Sistema Nacional de Segurança Alimentar e Nutricional (Sisan Universidades), especialmente o apoio às açôes do Fórum Estadual de Segurança e Soberania Alimentar e Nutricional (Fessan/PE) nesse período e a realização de pesquisas de monitoramento sobre a situação da fome/insegurança alimentar em municípios pernambucanos e em comunidades quilombolas do estado.

De forma geral, evidenciam-se açôes no campo da extensão universitária no apoio aos movimentos sociais e populares para o enfrentamento à desestruturação do tecido social provocado pela pandemia e a necessidade imperativa de isolamento social.

\section{SOBRE AS INCUBADORAS DA UFPB E DA UFRPE}

A universidade pública e a extensão universitária possibilitam a experimentação de uma nova práxis acadêmica, na qual ensino-pesquisa-extensão são vivenciados conjuntamente, como um "trabalho social útil", conforme expóe Melo Neto (2004, p. 53).

Extensão, como trabalho social útil com intencionalidade de conectar o ensino e a pesquisa, passa a ser agora exercida pela universidade e por membros de uma comunidade sobre a realidade objetiva. Um trabalho cooparticipativo que traz consigo as tensões de seus próprios componentes em ação e da própria realidade objetiva. Um trabalho onde se buscam objetos de pesquisa para a construção do conhecimento novo ou reformulaçóes das verdades existentes. Esses objetos pesquisados serão os constituintes de outra dimensão da universidade: o ensino. É também um trabalho de busca de objeto de pesquisa. A extensão configura-se e concretiza-se como trabalho social útil, imbuído da intencionalidade de pôr em mútua correlação o ensino e a pesquisa. Portanto, é social na medida em que não será uma tarefa individual; é útil, considerando que esse trabalho deverá expressar algum interesse e atender a uma necessidade humana. É, sobretudo, um trabalho que tem na sua origem a intenção de promover o relacionamento entre ensino e pesquisa. Nisto, e fundamentalmente nisto, diferencia-se das dimensóes outras da universidade, tratadas separadamente: o ensino e a pesquisa.

Nesse sentido, como programa de extensão universitária, o papel das incubadoras universitárias de apoio e assessoramento a experiências de economia solidária é estratégico, abrangendo assim aspectos econômicos, sociais, políticos e culturais para o assessoramento de grupos e organizaçóes coletivas de trabalhadores, objetivando desenvolver formas de gestáo mais democráticas e participativas para a geração de trabalho e renda (Addor e Laricchia, 2018). Existem atualmente dezenas de projetos dessa natureza em universidades e institutos federais de educação de todos os estados do Brasil. ${ }^{5}$

A Incubes/UFPB foi criada em 2001 e se configura como importante referência na Paraíba no apoio a grupos e empreendimentos de economia solidária (EES). ${ }^{6}$ Nestes quase dezenove anos, foram inúmeras ações de assessoramento e formação técnica aos grupos populares, movimentos sociais e trabalhadores(as) dos EES. O Nuplar, criado em 2014, plasmou as açóes

5. Para mais informações sobre as atividades das incubadoras universitárias de apoio a empreendimentos de economia solidária no Brasil, ver Perissé et al. (2017).

6. Sobre o conceito de empreendimentos de economia solidária e suas dimensões estruturais no Brasil, ver Silva (2017a). 
de três grupos de pesquisa e extensão da UFPB (Incubes, Grupo de Pesquisa em Extensão Popular - Extelar e Observatório de Políticas Culturais - Observacult), ${ }^{7}$ constituindo-se como núcleo interdisciplinar que busca contribuir com o desenvolvimento local e a geração de tecnologias sociais, promovendo novas perspectivas conceituais e práticas para o papel social da universidade, bem como na reflexão de questôes epistemológicas quanto ao exercício da pesquisa, do ensino e da extensão na área da economia solidária, da educação popular, da extensão popular, da cultura, da segurança alimentar e demais temas correlatos.

A Incubacoop/UFRPE é uma das pioneiras no Brasil no campo das incubadoras tecnológicas de cooperativas populares (ITCPs), criada em 1998. Filiada à rede de ITCPs, a incubadora da UFRPE realizou em sua trajetória um conjunto significativo de açôes e projetos que a destacam como referência importante em metodologia de incubação. Por intermédio dos princípios da economia solidária e da educação popular, trabalha com catadores de materiais reciclados, constituição de grupos agroecológicos, turismo de base comunitária etc. A Incubacoop também atua no apoio e na execução de políticas públicas, especialmente no período dos governos Lula e Dilma (2003-2015), destacando-se a realização do Projeto Centro de Formação em Economia Solidária $(\mathrm{CFES})^{8}$ e a animaçáo da Rede de Formadores em Economia Solidária da Regiáo Nordeste. ${ }^{9}$ As açóes de incubação atuais concentram-se em dois territórios: no município de Bonito, com o fomento à produção agroecológica e o apoio à comercialização de alimentos da agricultura familiar pelo Mercado da Vida; e no município de Abreu e Lima, com o apoio às cooperativas de catadores de materiais recicláveis. Além disso, a Incubacoop participa direta ou indiretamente de um amplo conjunto de ações de extensão, ensino e pesquisa e contribui para o desenvolvimento de projetos e programas no campo das políticas públicas e em articulaçáo com organizaçóes da sociedade civil e movimentos sociais.

\section{AÇÕES DA INCUBES/NUPLAR/UFPB NA PANDEMIA}

Este contexto é desafiador para as incubadoras universitárias, especialmente na continuidade de suas açôes de assessoramento aos EES, levando-se em consideração que suas metodologias se baseiam em processos e dinâmicas de imersão, diálogos permanentes e acompanhamento nos territórios/comunidades nos quais estão inseridos. Diante do quadro de isolamento social, é necessário encontrar e readequar formas de atuação e incubação, de modo a manter o foco na promoção do fortalecimento e autonomizaçáo dos grupos participantes, bem como no apoio ao desenvolvimento de seus territórios e de redes solidárias. Um dos pilares das açóes de incubação é a promoçáo da autogestáo. Este é um dos desafios metodológicos neste contexto de pandemia, ou seja, manter esta premissa em um momento táo delicado, no qual grande parte dos trabalhadores e trabalhadoras dos EES passa por dificuldades, necessitando de atendimentos básicos e emergenciais que garantam suas subsistências.

7. A Incubes foi criada em 2001; o Extelar, em 1999; e o Observacult, em 2013.

8. Sobre a experiência do CFES, ver Dubeux et al. (2012).

9. Sobre as políticas federais de economia solidária no Brasil, ver Faria (2011) e Silva (2018). 
Neste período de pandemia, podemos sintetizar as atividades desenvolvidas pela Incubes em quatro grandes blocos. ${ }^{10} \mathrm{O}$ primeiro está na continuidade das açóes de acompanhamento aos EES. Podemos ilustrar a partir de dois exemplos de EES que têm atuaçôes dentro do campus universitário. Com a suspensáo do semestre e das aulas presenciais, estes grupos, como tantos outros, se viram diante das dificuldades de manter suas atividades produtivas e de comercialização. No caso da Associação dos Agricultores(as) Familiares da Várzea Paraibana (Ecovarzea), que realiza há mais de dezoito anos uma feira agroecológica no campus 1 da UFPB, a suspensão de seu espaço de comercialização retirou uma das principais fontes de renda dos agricultores associados. Para apoiá-los, a Incubes vem contribuindo com o desenvolvimento de um sistema de compras on-line (a partir de um site) e entregas por drive thru. Isto tem possibilitado a comercialização de produtos agroecológicos, beneficiando não somente os agricultores(as), mas também toda a comunidade da UFPB e dos bairros vizinhos que têm na Feira da Ecovarzea uma referência de alimentação saudável.

Outro exemplo é o do grupo Ecolanches. Trata-se de uma lanchonete constituída por dez mulheres de uma comunidade vizinha à universidade e se notabiliza por produzir e comercializar, em um espaço da central de aulas da UFPB, exclusivamente alimentos saudáveis. No caso da Ecolanches, as açóes de apoio estáo sendo realizadas na própria comunidade, de modo a potencializar outras atividades que vêm sendo realizadas neste território, especialmente aquelas promovidas pelo Banco Comunitário de Desenvolvimento Jardim Botânico (EES também acompanhado pela Incubes). ${ }^{11}$ Assim, as açóes têm como estratégia articular as forças locais e promover conjuntamente alternativas de apoio às famílias e geração de renda na comunidade e/ ou entre grupos de economia solidária. Um exemplo é o lançamento da campanha de compras e doaçóes de produtos e alimentos a ser disponibilizado para a Ecolanches, cujo diferencial reside no envolvimento de consumidores, comerciantes da própria comunidade e outros grupos de economia solidária e da agricultura familiar da seguinte forma: o público em geral compra produtos de comerciantes locais e/ou EES; estes produtos são entregues à Ecolanches, que por sua vez prepara refeições para serem servidas em seu núcleo familiar e demais famílias da comunidade. Busca-se com esta ação apoiar uma dinâmica local de solidariedade, autogestáo e acesso à alimentação saudável.

Um segundo bloco de açôes está no entendimento de que um dos problemas no apoio aos EES e na construção de estratégias de geração de renda e acesso à alimentação é justamente a falta de informação sobre a situação dos EES, especialmente neste contexto de isolamento social. A defasagem de dados prejudica açóes de maior alcance que propiciem a estes grupos geração de renda a partir de suas particularidades e vocaçóes. Neste sentido, a Incubes está realizando um levantamento dos EES (inicialmente, somente daqueles em atuação na cidade de João Pessoa), buscando informaçôes que possibilitem três tipos de açôes. A primeira consiste em atualizar as informaçóes disponíveis sobre os EES, destacando as reais situaçóes em que se encontram neste contexto de pandemia. A segunda ação, e a partir dessas informaçóes, busca

10. Sobre a experiência recente da Icubes/Nuplar, ver Carneiro e Faria (2015).

11. Sobre as experiências de bancos comunitários de desenvolvimento e outras iniciativas de finanças solidárias no Brasil, ver Silva (2017b). 
dar visibilidade aos EES e construir com estes uma rede de colaboração e comercialização. Será criado um portal/site com as informaçóes dos EES, de seus produtos, seus modos de comercialização, seus contatos e outras informaçốes que possibilitem intercâmbios entre eles próprios e com os consumidores em geral. A terceira açáo busca propiciar a realizaçáo de feiras virtuais temáticas, de modo a sensibilizar a sociedade e potencializar a comercialização dos EES.

Um terceiro bloco de açáo da incubadora procura expandir esse levantamento de informaçôes para agregar outros grupos e coletivos que são atendidos pelo Nuplar e náo necessariamente estão organizados enquanto EES. Pelo caráter interdisciplinar do núcleo e da diversidade do público atendido, suas áreas de atuação e formas de organização, a ação busca traçar um diagnóstico socioeconômico abrangendo as condiçóes de trabalho e de inserção na economia solidária destes diversos segmentos e grupos. Esta era uma atividade prevista antes do isolamento social e ganha neste cenário uma importância maior, especialmente na identificação do grau de vulnerabilidade e da precariedade de inserção no mercado de trabalho destes segmentos e grupos. Além disso, visa traçar estratégias de geraçáo de renda e trabalho no período de isolamento e pós-isolamento. Assim, estamos no atual momento desenvolvendo a metodologia deste diagnóstico para ser aplicado na Paraíba.

Por fim, um quarto bloco de açáo realizada pela Incubes neste período de pandemia tem relação com o fortalecimento das políticas de segurança alimentar e nutricional (SAN) $\cdot{ }^{12} \mathrm{Em}$ parceria com a UFRPE e UFRN, estamos executando o Projeto Sisan Universidades que tem entre suas metas: i) o acompanhamento de trinta municípios por estado, na implementaçáo do projeto; e ii) o diagnóstico da situação de (in)segurança alimentar e nutricional de povos e comunidades tradicionais. Na Paraíba, a equipe da Incubes está auxiliando os municípios com informaçôes importantes de açóes e políticas de SAN que estes podem adotar e potencializar no atendimento às famílias e aos grupos em vulnerabilidade sociais. Além disso, em continuidade às açóes realizadas antes do período de pandemia, preparamos um curso de extensão com carga horária de quarenta horas, que será realizado por meio de ensino à distância (EAD).

Cabe ressaltar ainda que duas etapas foram executadas antes da realização deste curso EAD. A primeira foi dedicada à visita a trinta municípios paraibanos, e a segunda etapa foi a realização de oficinas divididas em seis circuitos territoriais. Estas duas etapas foram bem importantes para a construção do curso EAD, pois os conteúdos trabalhados nestas oficinas serviram de levantamento de temas e questôes que serão contemplados no curso. Estes conteúdos buscam propiciar, por um lado, a discussão de contextos mais amplos com os quais deve ser relacionado o tema da SAN, assim como a intersetorialidade necessária para seu fortalecimento, e, por outro lado, propiciar ferramentas e estratégias de enfrentamento da insegurança alimentar que tenham relaçáo com os contextos e as realidades práticas vivenciadas pelos participantes, especialmente agora neste período de pandemia. Foram abertas cem vagas e mais de 150 inscritos, inclusive de fora da Paraíba.

Outra ação vinculada ao Sisan Universidade foi a realização do diagnóstico na Paraíba dos Povos de Terreiro, com foco na comunidade Jurema. A aplicaçáo da pesquisa foi realizada

12. Sobre políticas no Brasil de segurança alimentar e nutricional, ver Silva e Valadares (2018). 
antes do período de isolamento social, e os dados da pesquisa têm sido importantes para dar visibilidade às condiçóes de insegurança alimentar destes povos tradicionais, bem como municiar os poderes públicos locais de informaçôes para o atendimento a este público, como, por exemplo, suas identificaçóes, localizaçóes e quantitativo de famílias vinculadas aos terreiros para a destinação de cestas de alimentos.

Esses quatro blocos de açóes constituem, em síntese, as atividades desenvolvidas pela Incubes no apoio aos diversos grupos, EES e movimentos sociais e populares no enfrentamento das consequências sociais da Covid-19 e seu necessário isolamento social como forma de preservação da vida. Os desafios metodológicos são imensos, mas independentemente do meio com o qual as açóes são desenvolvidas, mantém-se um princípio basilar de contribuir com processos de inclusão e de desenvolvimento social. É claro que as dificuldades impostas pelas formas de interação à distância limitam o alcance das ações, mas não as impedem de ser realizadas, ainda mais devido à urgência no atendimento às vulnerabilidades nas quais se encontram os territórios/comunidades. Ademais, a realização das açóes reforça o papel e a responsabilidade das universidades públicas e da extensão universitária na busca de estratégias de desenvolvimento de seus territórios de forma justa, solidária e democrática.

\section{AÇÕES DE EXTENSÃO DA UFRPE A PARTIR DA INCUBACOOP NA PANDEMIA}

Levou certo tempo até que a decisão do consórcio de universidades públicas e institutos federais de Pernambuco de suspender as atividades acadêmicas presenciais no dia 16 de março de 2020 fosse completamente assimilada. O que inicialmente apontava para uma suspensão momentânea, até passar a fase mais intensa de contágio, revelou-se logo como algo duradouro; e a complexidade do tratamento ao risco provocado pela pandemia exigiria uma adequação completa das rotinas cotidianas individuais e coletivas. Nos primeiros dias, após os ajustes nos cuidados requeridos pelo isolamento, com a suspensáo das atividades escolares e a nova dinâmica das tarefas reprodutivas, os coletivos responsáveis pela execução de açóes, projetos e atividades acadêmicas que estavam em andamento foram sendo retomados, adequados e reformulados para o novo contexto. ${ }^{13}$

Ao mesmo tempo, o aprofundamento da crise sanitária, potencializada pela crise econômica e social e pela ausência de vontade e capacidade políticas no plano federal, lançou os governos locais diante da tarefa de enfrentamento à pandemia, contando para isso com os meios técnicos e institucionais disponíveis. Dado o contexto geral de desigualdade social, pobreza e desemprego, rapidamente aprofundados após o contexto recente de crise econômica e política, surgiu logo o alerta para as imensas dificuldades que adviriam com o aumento do desemprego, da fome, da insegurança alimentar e das situaçóes de vulnerabilidade e risco social

13. No âmbito da Incubacoop, em um dos projetos executados com apoio do Ministério da Cidadania, um curso de formação com técnicos de assistência técnica e extensão rural (Ater) praticamente formatado e com seus participantes mobilizados precisou ser adiado. Uma pesquisa em andamento com comunidades quilombolas, sobre o tema da segurança alimentar, foi igualmente suspensa com metade da meta cumprida. 
e que atingiriam principalmente os territórios periféricos e precários das cidades brasileiras em geral e do Nordeste em particular.

O início do chamado trabalho remoto levou logo à constatação de que os estudantes que participavam dos projetos de extensão ou pesquisa apresentavam grande dificuldade de conectividade, seja por náo possuírem equipamento com capacidade para a execuçáo das plataformas usuais de chamadas on-line, seja pela indisponibilidade ou limitação do acesso à rede mundial de computadores em territórios precários, ou ainda pela falta de recursos para o pagamento desse serviço. Diga-se de passagem que alguns professores também apresentaram dificuldades iniciais com o trabalho remoto, tanto no tocante a equipamentos quanto ao acesso à internet, ou mesmo por náo estarem habituados com os procedimentos remotos de comunicação que se tornaram indispensáveis para a continuidade das açóes. Então, um primeiro esforço foi o de construir redes de conectividade e comunicação que permitissem a realizaçáo regular de encontros e encaminhamentos dos coletivos que integram as açóes e os projetos no âmbito da universidade.

Dentre as inúmeras iniciativas realizadas pela UFRPE no período da pandemia, especialmente as situadas no campo da extensão universitária, destacamos nesse momento três açóes que estão sendo desenvolvidas e contam com a participaçáo de professores e técnicos integrantes da Incubacoop/UFRPE.

\subsection{Projeto Mercado da Vida}

Este projeto ganhou impulso em 2015 por meio da parceria da incubadora com a prefeitura da cidade de Bonito, a partir da cessáo de um prédio público para a realização de feiras e comercializaçáo de produtos agroecológicos, articulando os temas da segurança e soberania alimentar e economia solidária (Dubeux e Batista, 2017). A incubadora atuava no território por intermédio do apoio e da assessoria técnica a um grupo de agricultores(as) em processo de transição para a produção agroecológica e que será a base para o fornecimento de alimentos ao Mercado da Vida. Além da comercialização de alimentos saudáveis, o local abriga também um grupo de mulheres da comunidade que produz artesanato. Com o início da pandemia e a impossibilidade de aglomeração de pessoas, as feiras do Mercado da Vida foram suspensas. Assim, os técnicos da incubadora no território passaram a participar da organização de cestas de alimentos, solicitadas pelo aplicativo whatsapp. Após a comercializaçáo de cestas por aproximadamente um mês, e com os cuidados e disponibilização de álcool gel, utilização de máscara e preservação do distanciamento, o mercado voltou ao funcionamento, sendo considerado serviço essencial durante a pandemia. Outra açáo do mercado foi o início da produção de máscaras pelo grupo de mulheres que produzem artesanato, cuja venda manteve a geração de renda para o grupo. 


\subsection{Projeto Sisan Universidades}

Outra ação importante acontece no âmbito do Projeto Sisan Universidades, iniciado em 2015 com o apoio do ex-Ministério do Desenvolvimento Social e Combate à Fome, depois transformado em Ministério da Cidadania. Esse projeto visa fundamentalmente fortalecer o Sistema Nacional de Segurança e Soberania Alimentar e Nutricional por meio do apoio a municípios dos estados de Pernambuco, Paraíba e Rio Grande do Norte, da realização de processos formativos e do desenvolvimento de pesquisas sobre o tema da segurança e soberania alimentar e nutricional nos territórios. A sua execução é coordenada pela UFRPE em parceria com a UFPB e UFRN, com equipes estaduais em cada estado e apoio do Conselho Estadual de Segurança Alimentar e Nutricional (Consea) e da Câmara Intersetorial de Segurança Alimentar e Nutricional (Caisans) estaduais. Em Pernambuco, o projeto havia realizado um diagnóstico em 33 municípios, e estava em curso uma pesquisa sobre a situação de insegurança alimentar nas comunidades quilombolas, contando para isso com o apoio das organizaçóes representativas das comunidades remanescentes de quilombos no estado. Com o início do período de isolamento social, foram definidas como prioridades a continuidade da sistematização dos dados provenientes das pesquisas em andamento, a realização de um processo sistemático de monitoramento da situação de fome e insegurança alimentar das comunidades quilombolas com a pandemia e a participação e o apoio nas açóes do Fessan/PE.

$\mathrm{O}$ monitoramento da situação de fome e insegurança alimentar junto às comunidades quilombolas está em curso, tendo como objetivos principais a identificação das situaçôes de maior vulnerabilidade e risco nas comunidades, conferir mais visibilidade pública às condiçóes dos territórios quilombolas durante a pandemia e mobilizar o poder público para a garantia do direito humano à alimentação adequada dessas comunidades.

Em apoio às ações emanadas do fórum estadual, a equipe do Projeto Sisan participou da elaboração de uma Carta Aberta do Fessan/PE, lançada em 31 de março de 2020, apontando um conjunto de medidas a serem tomadas pelos governos estadual e municipais para o enfrentamento à pandemia, como a criação de um Comitê Estadual e Municipais de Emergência pelas instâncias que tratam da SAN, interrupção dos despejos e reintegraçóes de posse, continuidade do Programa Nacional de Alimentação Escolar (PNAE), políticas de emergência para a agricultura familiar etc. Ao mesmo tempo, as várias dezenas de instituiçóes que assinaram a carta assumiram o compromisso de, entre outros, acompanhar e monitorar as ações de enfrentamento ao coronavírus. Nesse sentido, o Fessan/PE, com o apoio do Projeto Sisan Universidades, vem realizando o monitoramento das açôes de enfrentamento à pandemia emanadas dos governos estadual e municipais, visando especialmente publicizar e exigir do poder público ações efetivas para se evitar a deterioração das condiçóes de vida e o aprofundamento das desigualdades decorrentes da crise sanitária. 


\subsection{Projeto de criação da Universidade Popular dos Movimentos Sociais}

Uma ação que está sendo realizada com a participação da Incubacoop, de caráter mais estruturante, é o projeto de criação da UPMS, em parceria com as organizaçôes da sociedade civil: Serviço de Tecnologia Alternativa (Serta) ${ }^{14}$ e Escola Quilombo dos Palmares (Equip). ${ }^{15}$

A UPMS em Pernambuco, uma iniciativa firmada na obra do professor Boaventura de Sousa Santos, nasce da articulação de diferentes movimentos sociais e setores militantes da academia, no contexto dos primeiros anos do Fórum Social Mundial. É uma proposta intercultural de superação da dicotomia entre universidades e movimentos sociais e parte de uma articulação mais ampla de construção de educação popular com uma larga trajetória no continente latino-americano, tendo como referência a obra do educador Paulo Freire. ${ }^{16}$

Em Pernambuco, desde agosto de 2019, estamos desenvolvendo ações que culminaram em uma oficina em dezembro do mesmo ano com a presença de mais de trinta coletivos (movimentos sociais, ONGs, núcleos de pesquisa) e de intelectuais de diferentes universidades. $\mathrm{Na}$ carta-compromisso, firmada ao fim da oficina, nos comprometemos a seguir realizando atividades político-pedagógicas que seriam construídas de forma horizontal, respeitando os princípios e as pautas dos movimentos e das instituiçóes envolvidas.

A parceria com essas duas importantes entidades de Pernambuco, Serta e Equip, possibilitará à UFRPE um campo fértil de diálogo e possibilidades de projetos de ensino, pesquisa e extensão. Com a parceria consolidada, poderemos também reforçar visitas técnicas, contribuindo de forma significativa com o bacharelado em agroecologia e o Programa de Pós-Graduação em Agroecologia e Desenvolvimento Territorial, ambos da UFRPE. Será possível ainda pensar em estágios para estudantes de diferentes cursos.

\section{CONSIDERAÇÕES FINAIS}

Uma primeira constatação diz respeito à importância de os projetos de extensão, pesquisa e ensino universitários construírem açóes efetivas para além das fronteiras institucionais, seja pela elaboração e execução de projetos entre diferentes incubadoras universitárias, como é o caso do Projeto Sisan Universidades (UFRPE, UFPB e UFRN), seja das universidades com as organizaçóes sociais.

O cenário pós-pandemia pode abrir possibilidades de construção de novas formas de atuação das instituiçóes federais de ensino superior que aprofundem o seu enraizamento na sociedade, em que a luta pela democratização das relaçóes sociais e econômicas e da própria universidade brasileira andam juntas. Nas experiências desenvolvidas pelas incubadoras aqui relatadas, um aspecto importante é que todas elas procuram reconectar o político e o social no econômico, afastando o economicismo enquanto ideologia que legitima as desigualdades e a exploração.

14. Disponível em: <http://www.serta.org.br>.

15. Disponível em: <http://www.equip.org.br>.

16. Disponível em: <http://www.universidadepopular.org>. 
Do apoio e fomento às iniciativas de geração de trabalho associado e renda, tendo como princípio a autogestão, à formação de redes e cadeias produtivas solidárias, à organização comunitária que implementa processos endógenos de desenvolvimento, com apoio do poder público e das universidades públicas, ao movimento social organizado que ousa construir autonomamente seus processos de produção coletiva de conhecimentos, há um imenso campo de experiências que poderão dar azo a transformaçóes substantivas na nossa forma de ver e viver no mundo.

\section{REFERÊNCIAS}

ADDOR, F.; LARICCHIA, C. R. (Orgs.). Incubadoras tecnológicas de economia solidária. Rio de Janeiro: Ed. UFRJ, 2018.

CARNEIRO, V. G.; FARIA, M. S. Economia solidária e sociedade. João Pessoa/PB: Editora do CCTA/UFPB, 2015.

DUBEUX, A. et al. A construção do conhecimento em economia solidária: sistematização de experiências no chão do trabalho e da vida no Nordeste. Recife: F\&A Gráfica e Editora Ltda., 2012.

DUBEUX, A.; BATISTA, M. P. Agroecologia e economia solidária: um diálogo necessário à consolidaçáo do direito à soberania e segurança alimentar e nutricional. Revista Redes, v. 22, p. 227-249, 2017.

FARIA, M. S. Oito anos da Secretaria Nacional de Economia Solidária (Senaes): significados e perspectivas. Mercado de Trabalho: conjuntura e análise, Brasília, n. 48, 2011.

FREIRE, P. Extensáo ou comunicação? Rio de Janeiro: Paz e Terra, 2006.

MELO NETO, J. F. Extensão universitária é trabalho. João Pessoa: Ed. UFPB, 2004.

PERISSÉ, C. et al. A avaliação do Proninc 2017: metodologia e resultados. Mercado de Trabalho: conjuntura e análise, Brasília, n. 63, 2017.

SANTOS, B. S. A gramática do tempo: para uma nova cultura política. Porto: Afrontamento, 2006.

SILVA, S. P. Análise das dimensóes socioestruturais dos empreendimentos de economia solidária no Brasil. Brasília: Ipea, 2017a. (Texto para Discussão, n. 2271).

Economia solidária e finanças de proximidade. Brasília: Ipea, 2017b. (Texto para Discussão, n. 2270).

SILVA, S. P. A política de economia solidária no ciclo orçamentário nacional (2004-2018): inserção, expansão e crise de paradigma. Brasília: Ipea, 2018. (Texto para Discussão, n. 2434). SILVA, S. P.; VALADARES, A. A. Segurança alimentar e nutricional. In: LOZARDO, E. et al. (Orgs.). Desafios da naçáo. v. 2. Brasília: Ipea, 2018. 